\title{
Development and Evaluation of Environmentally Benign Aqueous Two Phase Systems for the Recovery of Proteins from Tannery Waste Water
}

\author{
Selvaraj Raja and Vytla Ramachandra Murty \\ Department of Biotechnology, Manipal Institute of Technology, Karnataka Manipal 576104, India \\ Correspondence should be addressed to Selvaraj Raja, rajaselvaraj@gmail.com \\ Received 29 September 2012; Accepted 11 November 2012 \\ Academic Editors: P. V. Bonnesen and G. D’Errico
}

Copyright (C) 2012 S. Raja and V. R. Murty. This is an open access article distributed under the Creative Commons Attribution License, which permits unrestricted use, distribution, and reproduction in any medium, provided the original work is properly cited.

Aqueous two phase systems (ATPSs) containing high molecular weight polyethylene glycol, PEG (10000), and completely biodegradable citrate salts (sodium citrate, potassium citrate, and ammonium citrate) with water were developed to recover the waste water proteins from a model tannery waste water system. The variations in the phase diagram were explained on the basis of ionic radius of cations, Gibbs free energy of hydration $\left(\Delta G_{\text {hydation }}\right)$ of cations, and effective excluded volume (EEV) of salts. The salting-out capability of the cations followed the sequence: Sodium citrate $>$ Potassium citrate $>$ Ammonium citrate. Setschenow-type equations were used to correlate tie-line compositions. During partitioning studies, recovery of tannery waste water proteins in PEG 10000 + Sodium citrate ATPS was found superior to other systems. It was possible to recover $95.86 \%$ of proteins from tannery waste water in the bottom phase with PEG $1000030 \%(\mathrm{w} / \mathrm{w})+$ Sodium citrate $13 \%(\mathrm{w} / \mathrm{w})$ at $30^{\circ} \mathrm{C}$. The partition coefficients were correlated with the salt compositions by a quadratic equation and the coefficients were calculated.

\section{Introduction}

Leather industry is one of the prominent industries in Indian economy which potentially provides employment, growth, and export. Up to date, approximately 2000 tanneries are present in India [1] and the waste water generated from them is enormous. During leather processing the skin and hides have to undergo series of processes such as soaking, liming, dehairing, bating, and degreasing. When the skin is subjected to liming process, the collagen structure will be swollen and the fiber bundles are opened up. This step enables the removal of interfibrillary soluble proteins and other biomolecules [2]. The presence of these proteins in the tannery waste water (TWW) effluents increases the biological oxygen demand and chemical oxygen demand and leads to pollution. Currently research is focused on the recovery of valuables from waste effluent generated by the industries. Instead of merely letting off these effluents, the biomolecules present in them can be recovered, since these biomolecules find applications in food and pharmaceutical industries [3].

Thus in this context, a separation method, aqueous two phase system (ATPS) is employed to recover the soluble proteins present in the TWW. ATPS is based on liquid-liquid extraction principle and can be formulated by mixing two chemically differing hydrophilic polymers or one hydrophilic polymer and one salt with water above certain concentrations [4].

It has been proved that a salt-based ATPS is an efficient and economic method for the separation and purification of various biomolecules because of its versatile features like low cost, low interfacial tension, biocompatibility, and ease of scale-up $[4,5]$.

The properties of ATPS mainly depend on the phase components used for a particular system. More often polyethylene-glycol (PEG) is chosen as one of the phase forming components because of its availability at low cost and ease of phase separation with salts. The molecular 
weight (MW) of PEG affects the partition behavior of the biomolecules. It is the available free volume in the phases which determines the partition behavior of the biomolecules [6].

Literature [3] suggests that high MW PEG ( $>6000 \mathrm{~g} /$ gmol) with higher tie-line length (TLL $>30 \% \mathrm{w} / \mathrm{w}$ ) would be suitable to recover low molecular weight biomolecules from the fermentation broth. Therefore in the present study, a high MW PEG (10000) was taken and partitioning trends were analysed with higher TLL.

Conventionally inorganic salts like phosphates, sulfates are used with PEG to form ATPS. But these salts impose a threat to the environment by means of water pollution [7]. As a result, biodegradable, nontoxic citrate salts have gained attention to replace the inorganic salts in ATPS. As both PEG and the citrate salts are biodegradable and nontoxic in nature, the ATPSs formed by them are environmentally benign and ecofriendly.

The increase in ATPS consists of PEG/citrate salt articles in the recent years for the separation and purification of biomolecules like penicillin acylase $[8,9]$, hexokinase [10], $\alpha$ amylase [11, 12], bovine trypsin [13], proteases [14, 15], human antibodies [16], glycomacropeptide [17], plasmid DNA [18], lactate dehydrogenase [19], lectins [20], and extractive bioconversion of xylan [21] clearly implies that there is a strive towards environmentally benign ATPS. Very recently a PEG/citrate system was successfully used for textile dye removal [22].

Recovery of valuable biomolecules from waste effluents by using ATPS came into attention only in 2006 by the research group Saravanan et al. [23]. Now considerable interest is growing in recovering biomolecules from various industrial effluents like fish [24], dairy [25], and prawn [26] using the PEG/citrate systems. Remarkably, all these researchers have employed PEG/citrate salt system for the recovery.

Even though, Saravanan et al. [23] have recovered the soluble proteins from TWW, the main disadvantage in their ATPS was the use of sulfate salts which pose an environmental concern. Thence, in our lab, we have chosen environmentally benign citrate salts, namely, sodium citrate (SC), potassium citrate $(\mathrm{KC})$, and ammonium citrate (AC) with PEG 10000 to form ATPSs to recover the soluble proteins from the TWW.

In order to understand the partitioning behavior and obtain best operating conditions, the liquid-liquid equilibrium (LLE) data is essential for any ATPS. It is noteworthy here to mention that there are no reports available on LLE for PEG 10000 + Citrate salts in literature. Hence our primary goal is to develop the LLE at $30^{\circ} \mathrm{C}$ for the ATPS and then study the partitioning behavior of the TWW soluble proteins in the developed systems.

\section{Materials and Methods}

2.1. Materials. PEG 10000, citric acid, trisodium citrate, tripotassium citrate monohydrate were purchased from Merck and triammonium citrate was purchase from Loba chemicals, India. All the components were used without further purification and Millipore-Milli-Q water was used in all the experiments.

2.2. Construction of Binodal Curve. Titration method [4] was used to obtain binodal curves. A known amount of PEG stock solution was titrated with the salt solution till the first sign of turbidity which indicated the formation of two phases. To this, water was added to clear the turbidity (single phase) and the procedure was repeated to get more binodal points. During this procedure, the weight of PEG initially taken, the salt added to form turbidity and water added were carefully weighed with an analytical balance with a precision of $\pm 0.1 \mathrm{mg}$. All the experiments were done in duplicates and average values were reported.

2.3. Determination of Tie-Line Length. During partitioning studies, it is convenient to express the different thermodynamic properties of the coexisting phases using TLL which is defined as the difference in concentration of phase forming components of ATPS. It can be determined by the following equation and is expressed in weight percentage $(\% \mathrm{w} / \mathrm{w})$ :

$$
\mathrm{TLL}=\sqrt{\left[W_{s}^{T}-W_{s}^{B}\right]^{2}+\left[W_{\mathrm{PEG}}^{T}-W_{\mathrm{PEG}}^{B}\right]^{2}}
$$

where $W_{s}$ and $W_{\text {PEG }}$ are the concentrations of salt and PEG, respectively, and superscripts $T$ and $B$ represent top and bottom phases, respectively.

In order to determine TLL, a series of ATPSs were prepared by mixing appropriate amounts of PEG 10000 and sodium citrate, potassium citrate, or ammonium citrate solution in $15 \mathrm{~mL}$ graduated tubes. The total weight of the system was maintained at $10 \mathrm{~g}$ by the addition of MilliporeMilli-Q water. The solutions were mixed by rigorous vortexing and were centrifuged at $2000 \mathrm{rpm}$ for $10 \mathrm{~min}$ to speed up the separation process. The tubes were placed in a thermostatic water bath at $30^{\circ} \mathrm{C}$ for overnight to attain phase equilibrium and then the samples were withdrawn from the phases without disturbing the interface.

The equilibrium concentration of PEG in both phases was determined by refractive index measurements performed using an Abbe-type refractometer (Advance Research Instruments Co., New Delhi, Model R-4). The concentrations of sodium and potassium ions in the top and bottom phases were determined by flame photometry. The concentration of ammonium citrate was determined by conductivity measurements. All the samples were properly diluted so that the concentration would fall within the range calibrated.

2.4. Preparation of Tannery Waste Water Sample. The tannery waste water feed stock was prepared according to the method given by Saravanan et al. [23]. According to this method, a known weight of green raw skin/hides was taken for alkali operation. In this stage most of the nonfibrous proteins were removed as a waste. This sectional stream wastewater was used as a protein source in partition experiments to recover the soluble proteins. 
2.5. Partitioning Experiments. Partitioning experiments were done with same feed compositions of PEG and different salts to investigate the influence of them. Stock solutions of salts and PEG required at the various TLL were prepared by mixing appropriate amounts of them along with tannery waste water sample as described in the previous section.

2.6. Protein Concentration Determination. The protein concentration in the individual phases was determined by the method of Bradford method [27]. For the determination of protein concentration, samples withdrawn from each phase were diluted with a known amount of distilled water, and its absorbance was measured using Shimadzu spectrophotometer at $595 \mathrm{~nm}$. In order to make a necessary correction to avoid the interference of PEG and citrate, an identical solution of the corresponding phase without sample was used as a blank.

2.7. Partitioning Parameters. In ATPS, the important parameters which characterize the partitioning behavior of biomolecules are partition coefficient $K_{p}$, phase ratio, and yield (\%).

The partition coefficient is defined as

$$
K_{p}=\frac{\text { Concentration of crude protein in top phase }}{\text { Concentration of crude protein in bottom phase }} \text {. }
$$

The yield (\%) of the crude proteins in the bottom phase $Y_{p, B}$ is calculated by using the following formula:

$$
Y_{p, B}(\%)=\frac{100}{1+\left(V_{\text {top }} / V_{\text {bottom }}\right) K_{p}},
$$

where $V_{\text {top }}$ and $V_{\text {bottom }}$ are the volumes of top and bottom phases, respectively, and this ratio is known as phase ratio.

\section{Results and Discussions}

3.1. Binodal Curve. The binodal curve is a boundary line which separates the single phase area and the two-phase area. Any composition above this curve forms two-phase systems. The binodal curves for PEG $10000+$ SC, PEG $10000+\mathrm{KC}$, and PEG $10000+\mathrm{AC}$ systems at $30^{\circ} \mathrm{C}$ were developed and shown in Figure 1.

Several correlations are available in the literature to correlate the binodal data [28-31]. We have used a thirdorder polynomial (4) to describe binodal data for these systems. The fitted coefficients are shown in Table 1. The high regression coefficient $\left(R^{2}\right)$ value and lesser absolute average relative deviation (AARD) values suggest that the experimental data are well fitted with the correlations

$$
W_{P}=B_{0}+B_{1} W_{s}+B_{2} W_{s}^{2}+B_{3} W_{s}^{3} .
$$

The type of the salt and polymer used for the ATPS determines the shape and position of the binodal curve. From Figure 1 it is evident that the two-phase region changes as the salt type changes. In the present system the

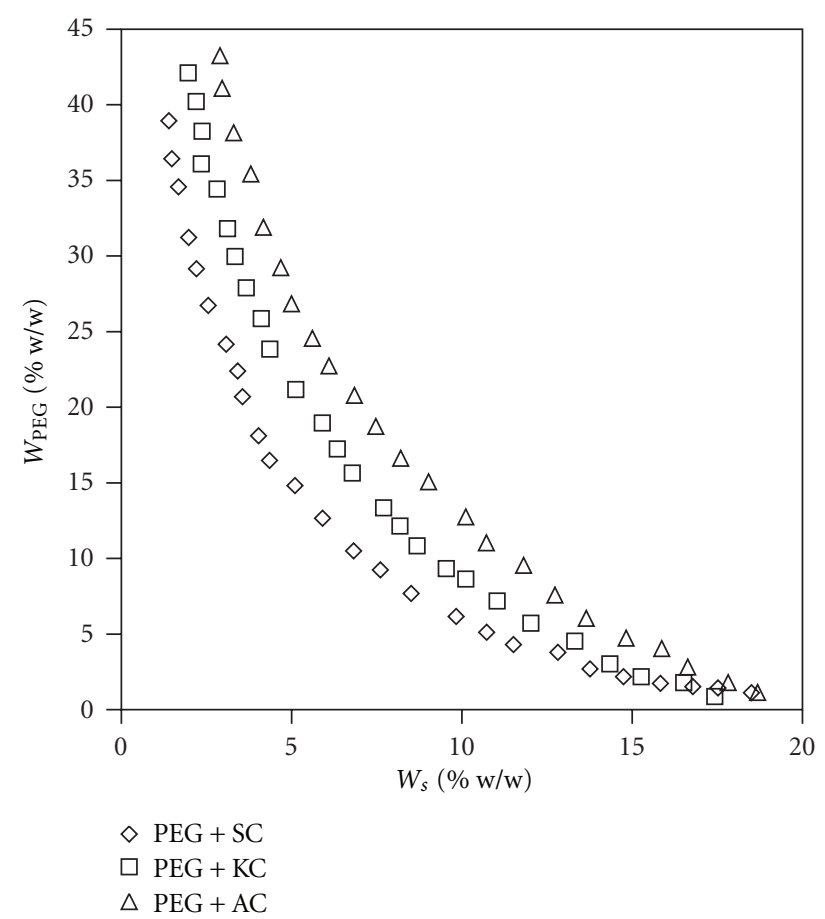

FIGURE 1: Effect of the type of salt on binodal curves for the PEG $10000\left(W_{\text {PEG }}\right)+$ Salt $\left(W_{s}\right)+$ Water systems at $30^{\circ} \mathrm{C}$.

predominant effect to promote the formation of ATPS is the "salting-out effect." This salting-out effect behavior can be explained by size of the cation, the Gibbs free energy of hydration ( $\Delta G_{\text {hydation }}$ ) of the cations, and effective excluded volume effect (EEV).

Ionic radius is the distance between the nucleus of an ion and the point up to which the nucleus has influence on its electron cloud. Since all the three salts analysed have a common anion (citrate) and different cations $\left(\mathrm{Na}^{+}, \mathrm{K}^{+}\right.$and $\mathrm{NH}_{4}{ }^{+}$), the salting out ability can be compared with respect to the ionic radius of the individual cations. The ionic radius of the cations $\mathrm{Na}^{+}, \mathrm{K}^{+}$, and $\mathrm{NH}_{4}{ }^{+}$in $\AA$ are $0.102,0.138$ [32], and 0.143 [33], respectively. It has been observed that the ionic radius is inversely proportional to the salting-out capacity in this case. And so, the increase in the cation size decreases the two-phase area and the cationic order for the formation of ATPS is $\mathrm{Na}^{+}>\mathrm{K}^{+}>\mathrm{NH}_{4}{ }^{+}$.

The salting-out ability of the salts follows the familiar Hofmeister series [34] and can be directly interrelated to the Gibbs free energies of hydration $\left(\Delta G_{\text {hydation }}\right)$ of the cations. It has been proved by researchers $[35,36]$ that when the salts have the same anion, then, the cation which has a more negative $\Delta G_{\text {hydation }}$ will be superior at salting-out PEG. By referring the $\Delta G_{\text {hydation }}$ of cations from the literature $[37,38]$ a lesser amount of salt SC $\left(\mathrm{Na}^{+}:-375 \mathrm{~kJ} / \mathrm{mol}\right)$ is required to salt out $\mathrm{PEG}$ as compared to potassium citrate $\left(\mathrm{K}^{+}\right.$: $-304 \mathrm{~kJ} / \mathrm{mol})$ or ammonium citrate $\left(\mathrm{NH}_{4}{ }^{+}:-285 \mathrm{~kJ} / \mathrm{mol}\right)$. The same behavior was observed in the present system and similar trend was shown in Figure 1. Consequently, the salting-out effect based on the $\Delta G_{\text {hydation }}$ can be summarized 
TABLE 1: Binodal curve coefficients of polynomial equation for various ATPSs.

\begin{tabular}{lcccccc}
\hline Type of ATPS & $B_{0}$ & $B_{1}$ & $B_{2}$ & $B_{3}$ & $R^{2}$ & AARD (\%) \\
\hline PEG + SC & 48.642 & -9.8801 & 0.7388 & -0.0188 & 0.9922 & 1.74 \\
PEG + KC & 58.285 & -10.357 & 0.7152 & -0.0179 & 0.9961 & 8.98 \\
PEG + AC & 66.686 & -10.573 & 0.6633 & -0.0154 & 0.9958 & 8.87 \\
\hline
\end{tabular}

TABLe 2: EEV values (5) of present ATPSs and Duraiayya et al., [41].

\begin{tabular}{lcc}
\hline Type of ATPS & $\begin{array}{c}\text { EEV (g/mol) } \\
\text { (Present study) }\end{array}$ & $\begin{array}{c}\text { EEV (g/mol) } \\
\text { (Duraiayya et al., } \\
[41])\end{array}$ \\
\hline PEG + SC & 96.43 & 52.42 \\
PEG + KC & 94.61 & 51.16 \\
PEG + AC & 68.73 & 38.96 \\
\hline
\end{tabular}

as $\mathrm{Na}^{+}>\mathrm{K}^{+}>\mathrm{NH}_{4}{ }^{+}$which is in concordant with the simple Hofmeister series.

Effective excluded volume characterizes the acceptableness of a particular salt by the hydrophilic polymer, PEG with water as a solvent to form an ATPS. It has been cited in the literature that increase in EEV value, increases the salting-out ability of a salt [39]. Hence, herein we made an attempt to explain the binodal behavior with respect to EEV. It was first presented by Guan et al. [40] for aqueous polymer-polymer system which was based on statistical geometry. Similar type of equation was used for the present system

$$
\ln \left(\operatorname{EEV} \frac{W_{\mathrm{PEG}}}{M_{\mathrm{PEG}}}\right)+\left(\operatorname{EEV} \frac{W_{s}}{M_{s}}\right)=0
$$

where EEV is the effective excluded volume, $M_{\mathrm{PEG}}$ and $M_{S}$ are the molecular weight of PEG and the salt, respectively. The EEV values were calculated by regression analysis of the model equation (5) and given in Table 2.

In the investigated systems it has been observed from Table 2 that ATPS which contained PEG + Sodium citrate has the maximum value of EEV and thus has the highest saltingout ability. Therefore, the salting-out ability is in the order of $\mathrm{SC}>\mathrm{KC}>\mathrm{AC}$. The same behavior is manifested in the phase diagram (Figure 1) by a position shift of the binodal curve towards the leftward thereby decreases the single-phase area. As a result, relatively a lesser concentration of sodium citrate is needed to form a two-phase system as compared to other salts. Recently, comparable results were obtained by Wang et al. [39] and concluded that the EEV of Sodium sulfate $>$ Ammonium sulfate and Potassium citrate $>$ Ammonium citrate.

In order to validate the EEV values of the present investigations, they were compared with data given by Duraiayya et al. [41]. From the LLE data of PEG 4000 + citrate salts at $30^{\circ} \mathrm{C}$, the EEV values were calculated and listed in Table 2. The results showed the same trend of $\mathrm{SC}>\mathrm{KC}>\mathrm{AC}$. The high values of EEV in our system may be due to the high MW PEG (10000) used, since increase in MW of the polymer often increases the EEV [24].
3.2. Tie-Line Compositions and Correlations. The equilibrium phase compositions of the two phases were related by TLL. A series of TLL in the two-phase region of the binodal curve were investigated and given in Table 3. Identical feed compositions were used for all three types of salts and the individual phases were analyzed as described earlier. All the experiments were performed in triplicates and the uncertainty of the concentration of phase components and partition coefficients were within \pm 2 and $\pm 1 \%$, respectively. It is apparent from Table 3 that the increase in TLL decreases the concentration of PEG in the bottom phase and increases the salt concentration and vice versa. This is because of the increase in hydrophobicity of the phases as the TLL increases.

In general, for organic solvent systems the tie-lines are parallel but a significant deviation occurs for ATPS. As shown in Figures 2, 3, and 4, the tie-lines are not essentially parallel for all the systems studied.

The tie-line data were correlated with Setschenow-type equations [42] in order to examine the reliability of the phase compositions. This Setschenow-type concept is also based on salting-out ability of salts

$$
\ln \left(\frac{m_{\mathrm{PEG}}^{T}}{m_{\mathrm{PEG}}^{B}}\right)=K_{\mathrm{PEG}}\left(m_{\mathrm{PEG}}^{B}-m_{\mathrm{PEG}}^{T}\right)+K_{s}\left(m_{S}^{B}-m_{S}^{T}\right),
$$

where $K_{\mathrm{PEG}}$ and $K_{s}$ are the parameter relating the activity coefficient of PEG to its concentration and the salting-out coefficient, respectively. " $m$ " represents molality and the superscripts $T$ and $B$ represent top phase and bottom phase, respectively. The parameters of the above equations were calculated based on the tie-line data and shown in Table 4 and Figure 5.

It has been observed that the $K_{s}$ value was smallest for the ammonium citrate salt and it was in the order $\mathrm{SC}>\mathrm{KC}>$ $\mathrm{AC}$ which is in concordance with the salting-out ability of the cations and also with EEV values as described earlier.

3.3. Partitioning Studies. The partition coefficients were calculated by (2) and it was witnessed that irrespective of the salt system, the partition coefficient, $K_{p}$ values were lesser than 1 which confirms that the tannery waste water proteins preferentially partition towards the bottom phase. This is the common behavior of ATPS which contain citrate salts [43]. The citrate salts are more hydrophilic in nature than the PEG phase and attract soluble proteins present in the tannery waste water. Since most of the protein is transferred to the salt rich bottom phase, the PEG rich top phase can be recycled.

3.4. Effect of TLL on Partitioning. In order to analyze the effect of TLL on each system, the same feed compositions 
TABLe 3: Tie-line data for PEG $10000\left(W_{\text {PEG }}\right)+$ citrate salt $\left(W_{s}\right)+$ water system at $30^{\circ} \mathrm{C}$.

\begin{tabular}{|c|c|c|c|c|c|c|c|c|}
\hline \multicolumn{2}{|c|}{ Feed } & \multicolumn{2}{|c|}{ Top phase } & \multicolumn{2}{|c|}{ Bottom phase } & \multirow{2}{*}{ TLL\% } & \multirow{2}{*}{$K_{p}$} & \multirow{2}{*}{ Yield \% } \\
\hline$W_{\mathrm{PEG}}(\% \mathrm{w} / \mathrm{w})$ & $W_{\mathrm{s}}(\% \mathrm{w} / \mathrm{w})$ & $W_{\mathrm{PEG}}(\% \mathrm{w} / \mathrm{w})$ & $W_{\mathrm{s}}(\% \mathrm{w} / \mathrm{w})$ & $W_{\mathrm{PEG}}(\% \mathrm{w} / \mathrm{w})$ & $W_{\mathrm{s}}(\% \mathrm{w} / \mathrm{w})$ & & & \\
\hline \multicolumn{9}{|c|}{ PEG $10000+$ sodium citrate + water } \\
\hline 22.00 & 9.00 & 29.75 & 1.98 & 2.01 & 21.22 & 33.76 & 0.346 & 84.01 \\
\hline 24.00 & 10.00 & 34.03 & 1.51 & 1.02 & 23.21 & 39.50 & 0.308 & 88.30 \\
\hline 26.00 & 11.00 & 38.21 & 0.99 & 0.92 & 25.15 & 44.43 & 0.274 & 90.35 \\
\hline 28.00 & 12.00 & 40.11 & 0.52 & 0.71 & 28.57 & 48.30 & 0.235 & 95.08 \\
\hline 30.00 & 13.00 & 42.02 & 0.23 & 0.51 & 32.33 & 52.47 & 0.216 & 95.86 \\
\hline \multicolumn{9}{|c|}{ PEG $10000+$ potassium citrate + water } \\
\hline 22.00 & 9.00 & 32.01 & 2.97 & 1.65 & 19.88 & 34.79 & 0.313 & 80.99 \\
\hline 24.00 & 10.00 & 37.22 & 2.54 & 1.12 & 24.11 & 42.12 & 0.265 & 82.03 \\
\hline 26.00 & 11.00 & 38.34 & 2.12 & 0.76 & 26.02 & 44.54 & 0.228 & 87.28 \\
\hline 28.00 & 12.00 & 40.04 & 1.52 & 0.54 & 27.96 & 47.53 & 0.218 & 91.07 \\
\hline 30.00 & 13.00 & 39.98 & 0.98 & 0.43 & 31.03 & 50.46 & 0.188 & 91.98 \\
\hline \multicolumn{9}{|c|}{ PEG 10000 + ammonium citrate + water } \\
\hline 22.00 & 9.00 & 33.23 & 4.23 & 1.23 & 18.89 & 35.24 & 0.211 & 80.96 \\
\hline 24.00 & 10.00 & 38.13 & 4.01 & 1.01 & 21.12 & 40.84 & 0.176 & 82.56 \\
\hline 26.00 & 11.00 & 41.01 & 3.34 & 0.75 & 23.09 & 44.79 & 0.151 & 85.29 \\
\hline 28.00 & 12.00 & 42.96 & 3.03 & 0.51 & 25.11 & 47.85 & 0.126 & 89.61 \\
\hline 30.00 & 13.00 & 45.05 & 2.71 & 0.43 & 26.87 & 50.76 & 0.101 & 92.17 \\
\hline
\end{tabular}

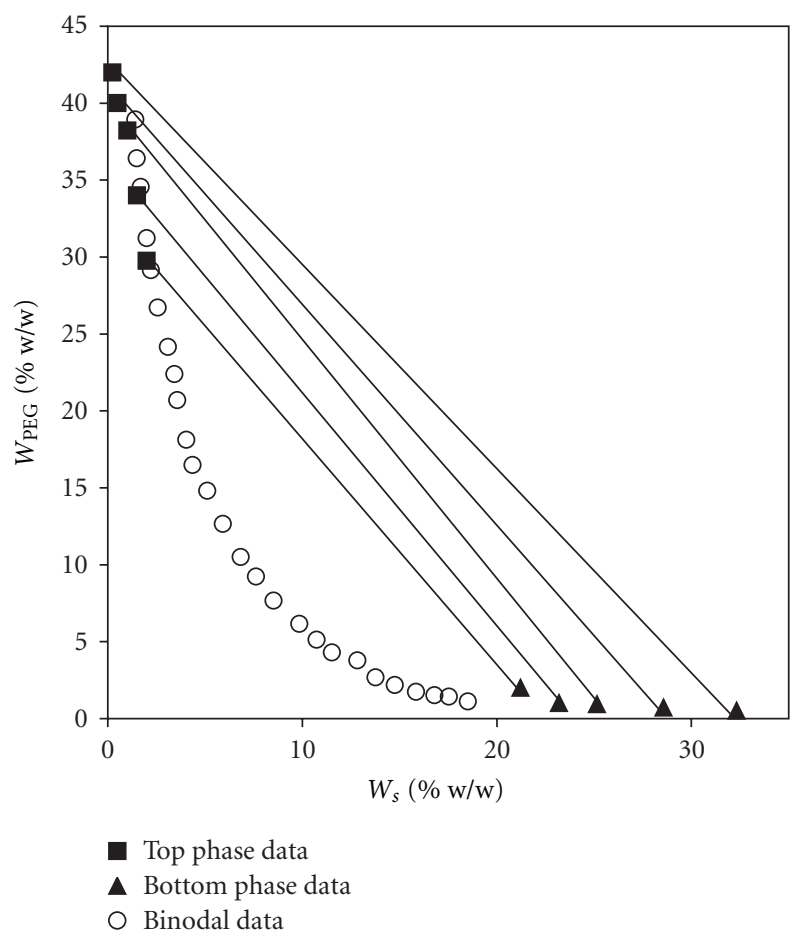

Figure 2: Binodal curve and tie-lines for PEG $10000\left(W_{\mathrm{PEG}}\right)+$ Sodium citrate $\left(W_{s}\right)+$ Water system at $30^{\circ} \mathrm{C}$.

were used for all the systems. It was observed that an increase in TLL caused an increase in protein transfer to the bottom phase (Table 3 ). In consequence, the partition coefficient decreased with increase in TLL as observed by many

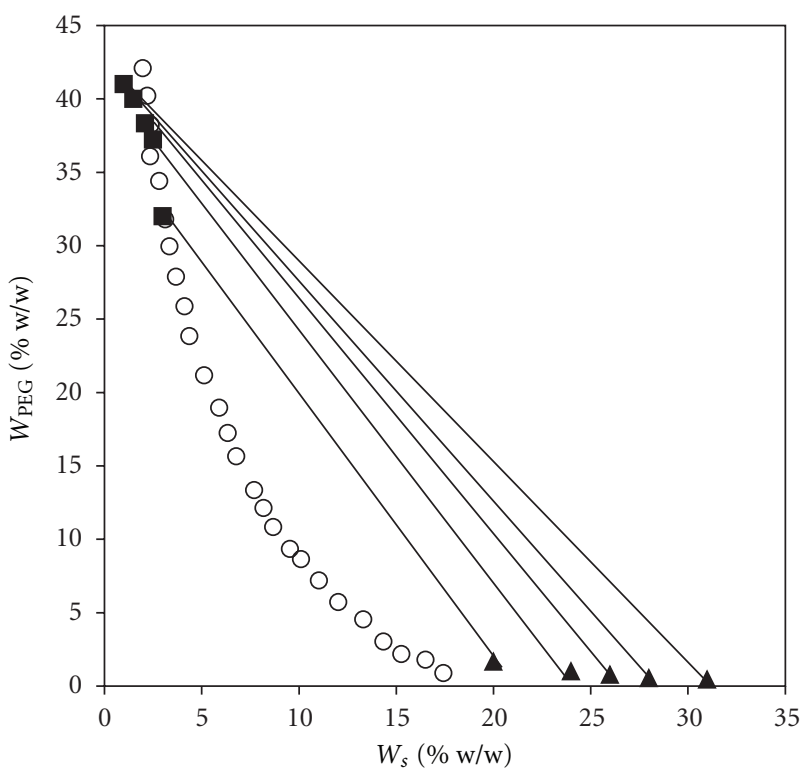

- Top phase data

$\Delta$ Bottom phase data

O Binodal data

Figure 3: Binodal curve and tie-lines for PEG $10000\left(W_{\mathrm{PEG}}\right)+$ Potassium citrate $\left(W_{s}\right)+$ Water system at $30^{\circ} \mathrm{C}$.

researchers [24, 44]. This effect can be due to volume exclusion effect because of the reduced space in the top phase which pushes the most of the proteins to the bottom phase [45]. 


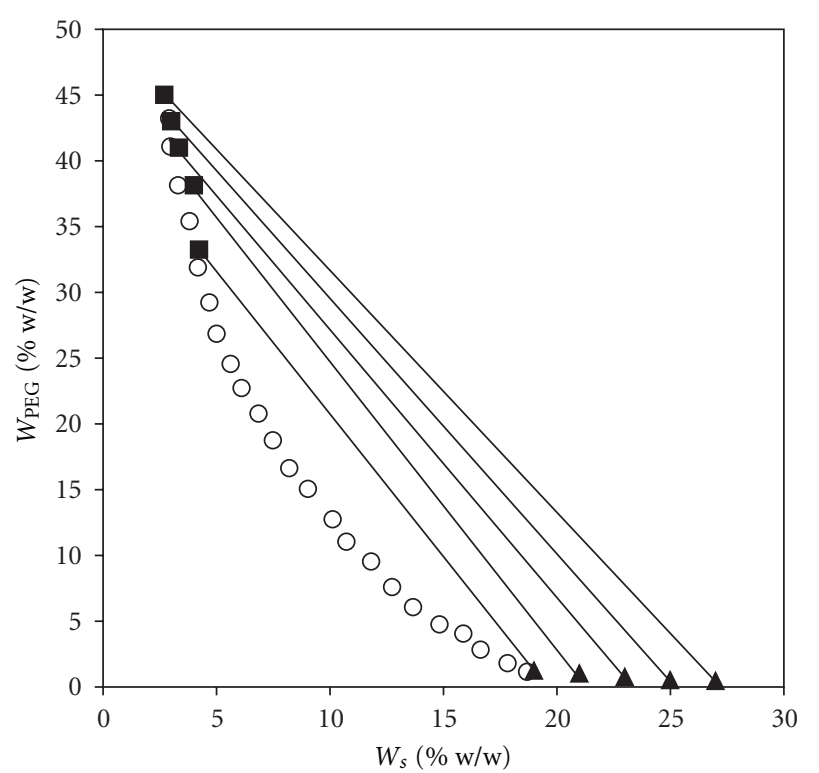

- Top phase data

A Bottom phase data

O Binodal data

Figure 4: Binodal curve and tie-lines for PEG $10000\left(W_{\text {PEG }}\right)+$ Ammonium citrate $\left(W_{s}\right)+$ Water system at $30^{\circ} \mathrm{C}$.

3.5. Effect of Salt Nature. The type and concentration of salt play a significant role on the partitioning. This is because of the nonuniform distribution of the salt ions between the phases and the different electric potential [46]. As observed in Table 3, there is a pertinent effect of the type of salt on partition coefficient. The protein yield was calculated for each experiment using (3) and best conditions for the maximum yield was found at $30 \%(\mathrm{w} / \mathrm{w})$ PEG $10000,13 \%$ (w/w) SC with $95.86 \%$ yield. For all the systems investigated, the $K_{p}$ was in the order: $\mathrm{SC}>\mathrm{KC}>\mathrm{AC}$. This trend should be undoubtedly because of the highest salting-out power of sodium citrate salt (as discussed earlier). Similarly, owing to the lesser salting-out capacity of the $\mathrm{KC}$ and AC, it is possible for these ATPSs to accommodate more protein in the bottom phase (decrease in $K$ ). Moreover these results reveal that there is a substantial interaction between the cations and PEG molecules and the interactions are highest for $\mathrm{Na}^{+}$. This is in agreement with the reported literature [47].

Furthermore, the variations in $K_{p}$ can be described by the variation in hydrophobicity of the phases. A double layer of ionic groups is formed between the charged groups of the proteins and the anions and cations present in the salt molecule. Because of the hydration effect, the protein molecules will be dehydrated and the hydrophobic zones are exposed as the concentration of salt is increased [48]. In general, the solubility of protein molecules in salt ions is related with respect to their position in Hofmeister series [34]. The effectiveness of this series for anions is citrate ${ }^{3-}>$ $\mathrm{SO}_{4}{ }^{2-}>\mathrm{HPO}_{4}{ }^{2-}>$ acetate ${ }^{-}>\mathrm{HCO}^{3-}>\mathrm{Cl}^{-}>\mathrm{NO}^{3-}>$ $\mathrm{ClO}^{3-}$ and for cations: $\mathrm{Mg}^{2+}>\mathrm{Li}^{+}>\mathrm{Na}^{+}>\mathrm{K}^{+}>\mathrm{NH}_{4}{ }^{+}$.

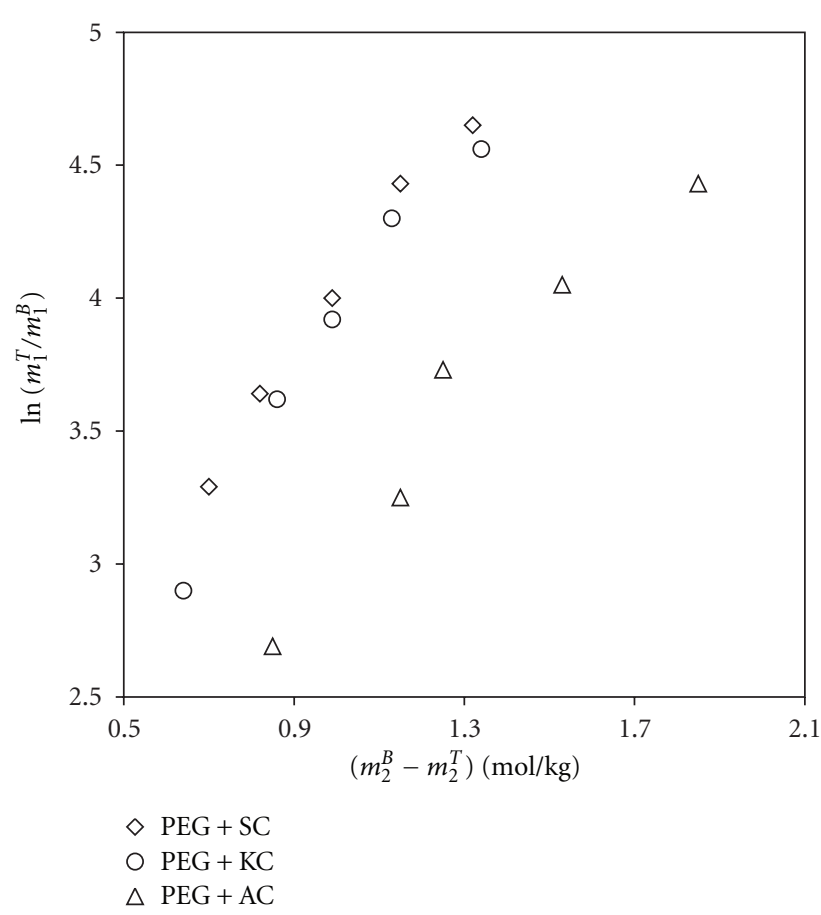

FIgURE 5: Setschenow-Type plots for the type of salt on binodal curves for the PEG 10000 + Citrate Salt + Water systems at $30^{\circ} \mathrm{C}$.

TABLe 4: Values of $K_{\mathrm{s}}$ and intercept of Setschenow-type equation (6) for the PEG 10000 + citrate + water systems.

\begin{tabular}{lccc}
\hline Type of ATPS & $K_{\mathrm{s}}(\mathrm{kg} / \mathrm{mol})$ & Intercept & $R^{2}$ \\
\hline PEG + SC & 2.3217 & 1.5709 & 0.9705 \\
PEG + KC & 2.235 & 1.7759 & 0.9879 \\
PEG + AC & 1.7384 & 1.3226 & 0.9565 \\
\hline
\end{tabular}

According to this series, the ions present in the left of the series decrease the protein solubility (high salting-out ability) by promoting hydrophobic interactions and thence relatively a more amount of protein moves towards the top phase $(K$ increases). Consequently the partition coefficient varies in the order $\mathrm{Na}^{+}>\mathrm{K}^{+}>\mathrm{NH}_{4}{ }^{+}$. as the system investigated presently has the common anion citrate and different cations. Therefore the Hofmeister series influences the partitioning of proteins in the present system.

3.6. Correlations for Partition Coefficient. Development of correlations for partition coefficient is difficult because its dependence on multifactor such as phase compositions, ionic strength, hydrophobicity, and so forth, Nevertheless, there are a few models available in the literature to correlate $K_{p}$. One of those well-known models is Diamond-Hsu model [49] for PEG + Dextran system which related ln $K_{p}$ with $\triangle$ PEG (difference in PEG concentration in top and bottom phases). Later in 1996, Ziqiang et al. [50] modified the Diamond-Hsu model for PEG + potassium phosphate 


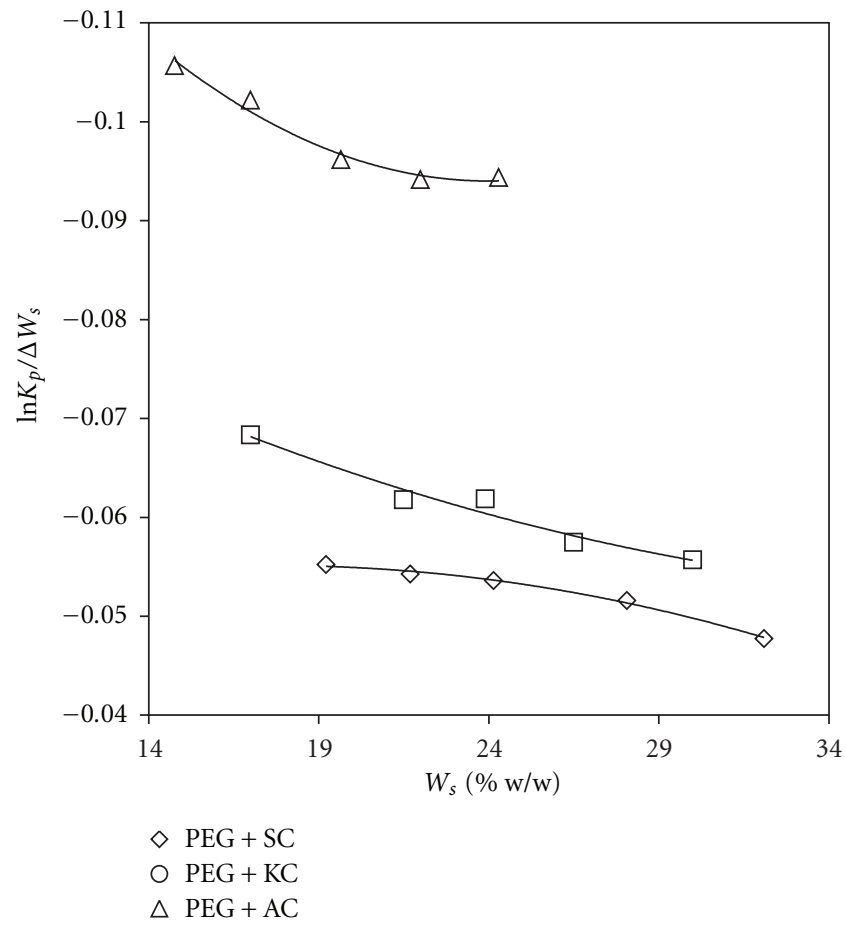

Figure 6: Correlation for tannery waste water protein partition coefficient according to (7) in PEG/Citrate salt system at $30^{\circ} \mathrm{C}$.

system for the partitioning of urokinase enzyme and deduced the following equation:

$$
\ln \left(\frac{K_{p}}{\Delta W_{s}}\right)=A+B \Delta W_{s}+C \Delta W_{s}^{2}
$$

where $\Delta W_{s}$ is the difference in salt concentrations between top and bottom phases and $A, B$, and $C$ are the regression coefficients.

Blázquez et al. [51] used a simple linear correlation $\ln K_{p}=A \Delta W_{s}$ to correlate $\alpha$-amylase partitioning in $\mathrm{PEG}+\mathrm{MgSO}_{4}$ system. Similar relationship was fitted for partitioning of caseinomacropeptide [52]. We have used the model proposed by Ziqiang et al. [50] to correlate the $K_{p}$ and the quadratic equation (7) was fitted to the data and shown in Figure 6.

It can be noticed that the increase in $\Delta W_{s}$ value for all types of salts decreases the $K_{p}$ value. Moreover, the different coefficient values (Table 5) for each of the salt suggest the presence of salt-protein interactions. The high values of $R^{2}$ and low values of AARD imply that model is adequate for the data.

\section{Conclusions}

Environmentally benign ATPSs consisted of PEG $10000+$ Sodium citrate + water, PEG 10000 + Potassium citrate + water, and PEG $10000+$ Ammonium citrate + water were taken for the study. The binodal curves and tie-line compositions were obtained and analysed. The effect of citrate salt on the position of binodal curve was described in terms of
TABLE 5: Regression coefficients according to (7) in PEG/citrate salt system at $30^{\circ} \mathrm{C}$.

\begin{tabular}{lccccc}
\hline Type of ATPS & $A$ & $B$ & $C$ & $R^{2}$ & AARD (\%) \\
\hline PEG + SC & -0.0443 & -0.0012 & $3 \times 10^{-5}$ & 0.9946 & 0.0624 \\
PEG + KC & -0.0981 & 0.0022 & $-3 \times 10^{-5}$ & 0.9615 & 0.0559 \\
PEG + AC & -0.1767 & 0.0069 & $-1 \times 10^{-4}$ & 0.9780 & 0.0453 \\
\hline
\end{tabular}

ionic radius, Gibbs free energy of hydration $\left(\Delta G_{\text {hydation }}\right)$ of cations, and effective excluded volume (EEV). In all the cases the salting-out strength of the cations behaved in the order: $\mathrm{Na}^{+}>\mathrm{K}^{+}>\mathrm{NH}_{4}^{+}$which conforms to Hofmeister series. The tie-line compositions were satisfactorily correlated with Setschenow-type equation. The partitioning of tannery waste water proteins was carried out with these compositions. It was found out that protein prefers to move to the bottom phase in all the systems and recycling of PEG was possible. An optimum yield of $95.86 \%$ in the bottom phase of ATPS with composition 30\%(w/w) PEG 10000 and 13\%(w/w) Sodium citrate at $30^{\circ} \mathrm{C}$ was obtained. Correlations for the partition coefficient were developed and verified. This study demonstrates the possibility of using environmentally benign PEG-citrate salt-water ATPS for the recovery of proteins from tannery waste water.

\section{References}

[1] S. Sanyal, S. Banerjee, and S. Majumder, "India's leather in the world market: exploration of recent trends," Trade and Development Review, vol. 3, pp. 22-58, 2010.

[2] R. B. Choudhary, A. K. Jana, and M. K. Jha, "Enzyme technology applications in leather processing," Indian Journal of Chemical Technology, vol. 11, no. 5, pp. 659-671, 2004.

[3] J. Benavides and M. Rito-Palomares, "Practical experiences from the development of aqueous two-phase processes for the recovery of high value biological products," Journal of Chemical Technology and Biotechnology, vol. 83, no. 2, pp. 133142, 2008.

[4] R. Hatti-Kaul, Aqueous Two Phase Systems: Methods and Protocols, Humana Press, Totowa, NJ, USA, 2000.

[5] A. B. Mageste, L. R. de Lemos, G. M. D. Ferreira et al., "Aqueous two-phase systems: an efficient, environmentally safe and economically viable method for purification of natural dye carmine," Journal of Chromatography A, vol. 1216, no. 45, pp. 7623-7629, 2009.

[6] H. Cabezas, "Theory of phase formation in aqueous twophase systems," Journal of Chromatography B, vol. 680, no. 1-2, pp. 3-30, 1996.

[7] F. Rahimpour, F. Feyzi, S. Maghsoudi, and R. Hatti-Kaul, "Purification of plasmid DNA with polymer-salt aqueous twophase system: optimization using response surface methodology," Biotechnology and Bioengineering, vol. 95, no. 4, pp. 627637, 2006.

[8] J. C. Marcos, L. P. Fonseca, M. T. Ramalho, and J. M. S. Cabral, "Application of surface response analysis to the optimization of penicillin acylase purification in aqueous two-phase systems," Enzyme and Microbial Technology, vol. 31, no. 7, pp. 1006-1014, 2002.

[9] G. Pazuki, M. Vossoughi, and V. Taghikhani, "Partitioning of penicillin $G$ acylase in aqueous two-phase systems of 
poly(ethylene glycol) 20000 or 35000 and potassium dihydrogen phosphate or sodium citrate," Journal of Chemical and Engineering Data, vol. 55, no. 1, pp. 243-248, 2010.

[10] G. G. G. Oliveira, D. P. Silva, I. C. Roberto, M. Vitolo, and A. Pessoa, "Partition behavior and partial purification of hexokinase in aqueous two-phase polyethylene glycol/citrate systems," Applied Biochemistry and Biotechnology A, vol. 108, no. 1-3, pp. 787-798, 2003.

[11] W. Zhi, J. Song, J. Bi, and F. Ouyang, "Partial purification of $\alpha$-amylase from culture supernatant of Bacillus subtilis in aqueous two-phase systems," Bioprocess and Biosystems Engineering, vol. 27, no. 1, pp. 3-7, 2004.

[12] W. Zhi, J. Song, F. Ouyang, and J. Bi, "Application of response surface methodology to the modeling of $\alpha$-amylase purification by aqueous two-phase systems," Journal of Biotechnology, vol. 118, no. 2, pp. 157-165, 2005.

[13] G. Tubío, B. Nerli, and G. Picó, "Partitioning features of bovine trypsin and $\alpha$-chymotrypsin in polyethyleneglycolsodium citrate aqueous two-phase systems," Journal of Chromatography B, vol. 852, no. 1-2, pp. 244-249, 2007.

[14] T. S. Porto, P. A. Pessôa-Filho, B. B. Neto et al., "Removal of proteases from Clostridium perfringens fermented broth by aqueous two-phase systems (PEG/citrate)," Journal of Industrial Microbiology and Biotechnology, vol. 34, no. 8, pp. 547-552, 2007.

[15] T. S. Porto, G. M. Medeiros e Silva, C. S. Porto et al., "Liquidliquid extraction of proteases from fermented broth by PEG/ citrate aqueous two-phase system," Chemical Engineering and Processing, vol. 47, no. 4, pp. 716-721, 2008.

[16] A. M. Azevedo, A. G. Gomes, P. A. J. Rosa, I. F. Ferreira, A. M. M. O. Pisco, and M. R. Aires-Barros, "Partitioning of human antibodies in polyethylene glycol-sodium citrate aqueous twophase systems," Separation and Purification Technology, vol. 65, no. 1, pp. 14-21, 2009.

[17] C. A. S. da Silva, J. S. R. Coimbra, E. E. G. Rojas, and J. A. C. Teixeira, "Partitioning of glycomacropeptide in aqueous twophase systems," Process Biochemistry, vol. 44, no. 11, pp. 1213 1216, 2009.

[18] G. A. Gomes, A. M. Azevedo, M. R. Aires-Barros, and D. M. F. Prazeres, "Purification of plasmid DNA with aqueous two phase systems of PEG 600 and sodium citrate/ammonium sulfate," Separation and Purification Technology, vol. 65, no. 1, pp. 22-30, 2009.

[19] R. F. F. de Araújo, T. S. Porto, D. B. G. Martins, R. F. Dutra, A. L. F. Porto, and J. L. D. L. Filho, "Partitioning of lactate dehydrogenase from bovine heart crude extract by polyethylene glycol-citrate aqueous two-phase systems," Fluid Phase Equilibria, vol. 301, no. 1, pp. 46-50, 2011.

[20] C. S. Porto, T. S. Porto, K. S. Nascimento et al., "Partition of lectin from Canavalia grandiflora Benth in aqueous twophase systems using factorial design," Biochemical Engineering Journal, vol. 53, no. 2, pp. 165-171, 2011.

[21] X. Li, Z. Lian, B. Dong, Y. Xu, Q. Yong, and S. Yu, "Extractive bioconversion of xylan for production of xylobiose and xylotriose using a PEG6000/sodium citrate aqueous two-phase system," Korean Journal of Chemical Engineering, vol. 28, pp. 1897-1901, 2011.

[22] D. Z. Ivetic, M. B. Sciban, V. M. Vasic, D. V. Kukic, J. M. Prodanovic, and M. G. Antov, "Evaluation of possibility of textile dye removal from wastewater by aqueous two-phase extraction," Desalination and Water Treatment. In press.

[23] S. Saravanan, J. R. Rao, T. Murugesan, B. U. Nair, and T. Ramasami, "Recovery of value-added globular proteins from tannery wastewaters using PEG-salt aqueous two-phase systems," Journal of Chemical Technology and Biotechnology, vol. 81, no. 11, pp. 1814-1819, 2006.

[24] R. Iyyaswami, P. D. Belur, B. Girish, and V. H. Nagaraj, "Development and evaluation of PEG-lithium citrate salt based aqueous two phase system and its application in partitioning of proteins from fish industry effluent," Separation Science and Technology, vol. 47, pp. 591-598, 2012.

[25] M. Perumalsamy and T. Murugesan, "Extraction of Cheese whey proteins ( $\alpha$-lactalbumin and $\beta$ - lactoglobulin) from dairy effluents using environmentally benign aqueous biphasic system," International Journal of Chemical and Environmental Engineering, vol. 3, pp. 55-59, 2012.

[26] D. Ramyadevi, A. Subathira, and S. Saravanan, "Central composite design application for optimization of aqueous twophase extraction of protein from shrimp waste," Journal of Chemical and Pharmaceutical Research, vol. 4, pp. 2087-2095, 2012.

[27] M. M. Bradford, "A rapid and sensitive method for the quantitation of microgram quantities of protein utilizing the principle of protein dye binding," Analytical Biochemistry, vol. 72, no. 1-2, pp. 248-254, 1976.

[28] M. T. Zafarani-Moattar and A. A. Hamidi, "Liquid-liquid equilibria of aqueous two-phase poly(ethylene glycol)-potassium citrate system," Journal of Chemical and Engineering Data, vol. 48, no. 2, pp. 262-265, 2003.

[29] T. Murugesan and M. Perumalsamy, "Liquid-liquid equilibria of poly(ethylene glycol) $2000+$ sodium citrate + water at $(25$, $30,35,40$, and 45$)^{\circ} \mathrm{C}$," Journal of Chemical and Engineering Data, vol. 50, no. 4, pp. 1392-1395, 2005.

[30] G. Tubío, L. Pellegrini, B. B. Nerli, and G. A. Picó, "Liquidliquid equilibria of aqueous two-phase systems containing poly(ethylene glycols) of different molecular weight and sodium citrate," Journal of Chemical and Engineering Data, vol. 51, no. 1, pp. 209-212, 2006.

[31] S. Saravanan, J. A. Reena, J. R. Rao, T. Murugesan, and B. U. Nair, "Phase equilibrium compositions, densities, and viscosities of aqueous two-phase poly(ethylene glycol) + poly (acrylic acid) system at various temperatures," Journal of Chemical and Engineering Data, vol. 51, no. 4, pp. 1246-1249, 2006.

[32] http://www.chemguide.co.uk/atoms/properties/atradius .html.

[33] http://cnx.org/content/m32956/latest/\#id8551717.

[34] R. A. Curtis and L. Lue, "A molecular approach to bioseparations: protein-protein and protein-salt interactions," Chemical Engineering Science, vol. 61, no. 3, pp. 907-923, 2006.

[35] Y. Pei, J. Wang, L. Liu, K. Wu, and Y. Zhao, "Liquid-liquid equilibria of aqueous biphasic systems containing selected imidazolium ionic liquids and salts," Journal of Chemical and Engineering Data, vol. 52, no. 5, pp. 2026-2031, 2007.

[36] M. T. Zafarani-Moattar and S. Hamzehzadeh, "Liquid-liquid equilibria of aqueous two-phase systems containing 1-butyl3-methylimidazolium bromide and potassium phosphate or dipotassium hydrogen phosphate at $298.15 \mathrm{~K}$," Journal of Chemical and Engineering Data, vol. 52, no. 5, pp. 1686-1692, 2007.

[37] Y. Marcus, "Thermodynamics of solvation of ions. Part 5.gibbs free energy of hydration at $298.15 \mathrm{~K}$," Journal of the Chemical Society, Faraday Transactions, vol. 87, no. 18, pp. 2995-2999, 1991.

[38] Y. Marcus and A. Rashin, "A simple empirical model describing the thermodynamics of hydration of ions of widely varying 
charges, sizes, and shapes," Biophysical Chemistry, vol. 51, no. 2-3, pp. 111-127, 1994.

[39] Y. Wang, J. Wang, J. Han, S. Hu, and Y. Yan, "Liquidliquid equilibrium of novel aqueous two-phase systems and evaluation of salting-out abilities of salts," Central European Journal of Chemistry, vol. 8, no. 4, pp. 886-891, 2010.

[40] Y. Guan, T. H. Lilley, and T. E. Treffry, "A new excluded volume theory and its application to the coexistence curves of aqueous polymer two-phase systems," Macromolecules, vol. 26, no. 15, pp. 3971-3979, 1993.

[41] R. Duraiayya, S. Arumugam, and S. Settu, "Equilibrium phase behavior of poly(ethylene glycol) 4000 and biodegradable salts at various temperatures $\left[(20,30 \text {, and } 40)^{\circ} \mathrm{C}\right]$," Journal of Chemical Engineering and Data, vol. 57, pp. 1112-1117, 2012.

[42] M. J. Hey, D. P. Jackson, and H. Yan, "The salting-out effect and phase separation in aqueous solutions of electrolytes and poly(ethylene glycol)," Polymer, vol. 46, no. 8, pp. 2567-2572, 2005.

[43] M. Perumalsamy and M. I. Batcha, "Synergistic extraction of bovine serum albumin using polyethylene glycol based aqueous biphasic system," Process Biochemistry, vol. 46, no. 2, pp. 494-497, 2011.

[44] K. Naganagouda and V. H. Mulimani, "Aqueous two-phase extraction (ATPE): an attractive and economically viable technology for downstream processing of Aspergillus oryzae $\alpha$ galactosidase," Process Biochemistry, vol. 43, no. 11, pp. 1293 1299, 2008.

[45] L. P. Malpiedi, G. Picó, and B. Nerli, "Features of partitioning pattern of two pancreatic enzymatic precursors: trypsinogen and chymotrypsinogen in polyethyleneglycol-sodium citrate aqueous biphasic systems," Journal of Chromatography B, vol. 870, no. 1, pp. 1-7, 2008.

[46] J. H. Han and C. H. Lee, "Effects of salts and poly(ethylene glycol)-palmitate on the partitioning of proteins and Bacillus subtilis neutral protease in aqueous two-phase systems," Colloids and Surfaces B, vol. 9, no. 1-2, pp. 109-116, 1997.

[47] I. S. Barberino do Nascimento, J. Sélia dos Reis Coimbra, J. P. Martins et al., "Partitioning of glutenin flour of special wheat using aqueous two-phase systems," Journal of Cereal Science, vol. 52, no. 2, pp. 270-274, 2010.

[48] R. C. F. Bonomo, L. A. Minim, J. S. R. Coimbra, R. C. I. Fontan, L. H. Mendes da Silva, and V. P. R. Minim, "Hydrophobic interaction adsorption of whey proteins: effect of temperature and salt concentration and thermodynamic analysis," Journal of Chromatography B, vol. 844, no. 1, pp. 6-14, 2006.

[49] A. D. Diamond and J. T. Hsu, "Correlation of protein partitioning in aqueous polymer two-phase systems," Journal of Chromatography, vol. 513, pp. 137-143, 1990.

[50] Z. Ziqiang, L. Mian, M. Lehe, and H. Zhaoxiong, "Measurement and correlation of partition coefficients of Urokinase in aqueous two-phase peg-potassium phosphate system," Chinese Journal of Chemical Engineering, vol. 4, no. 1, pp. 1927, 1996.

[51] G. Blázquez, F. Camacho, P. González-Tello, and F. J. Alarcón, "Partition coefficients of $\alpha$-amylase in aqueous two-phase systems PEG $+\mathrm{MgSO}_{4} \cdot 7 \mathrm{H}_{2} \mathrm{O}+\mathrm{H}_{2} \mathrm{O}$ at $298 \mathrm{~K}$," Biochimica et Biophysica Acta, vol. 1379, no. 2, pp. 191-197, 1998.

[52] C. A. S. da Silva, J. S. R. Coimbra, E. E. G. Rojas, L. A. Minim, and L. H. M. da Silva, "Partitioning of caseinomacropeptide in aqueous two-phase systems," Journal of Chromatography B, vol. 858, no. 1-2, pp. 205-210, 2007. 

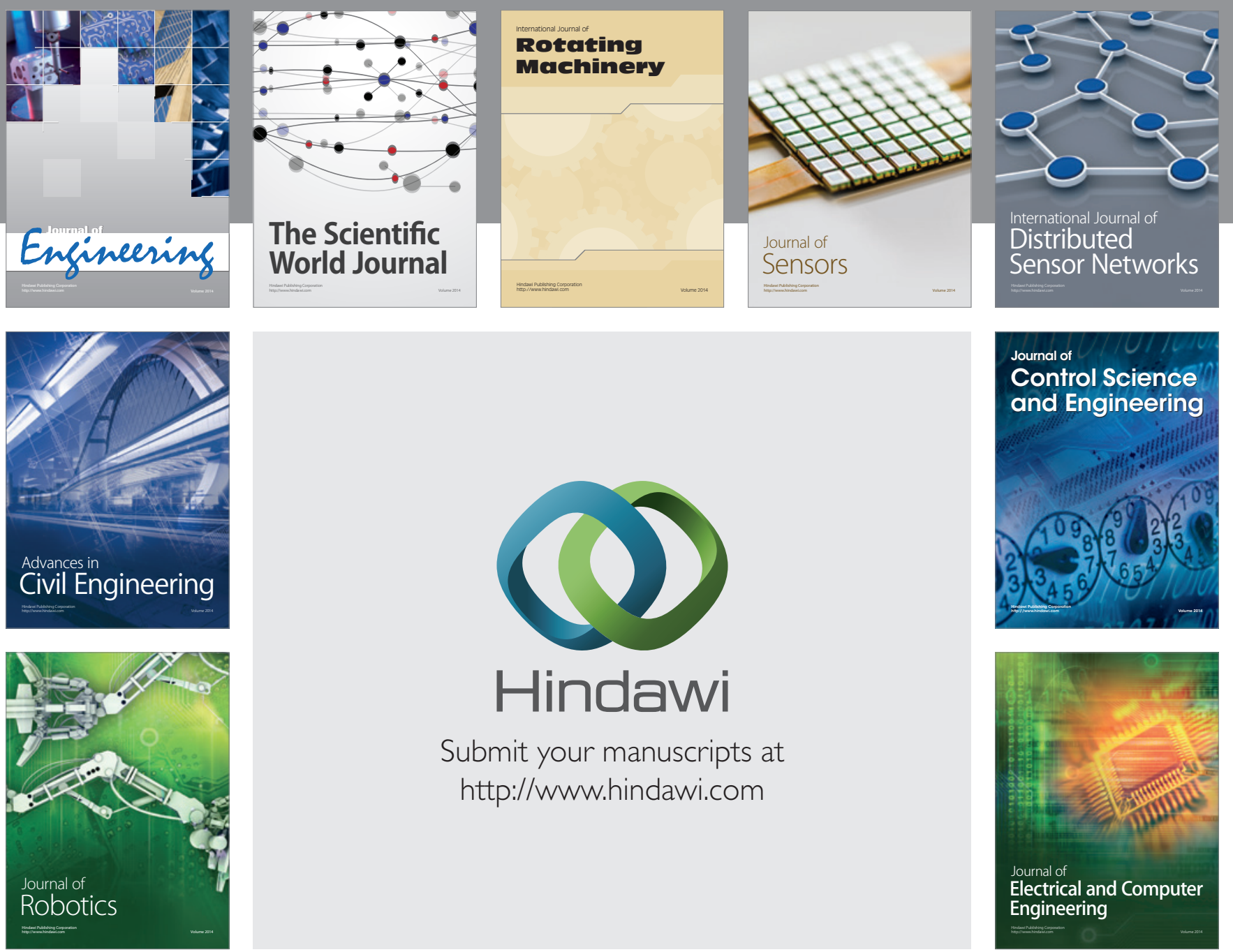

Submit your manuscripts at

http://www.hindawi.com
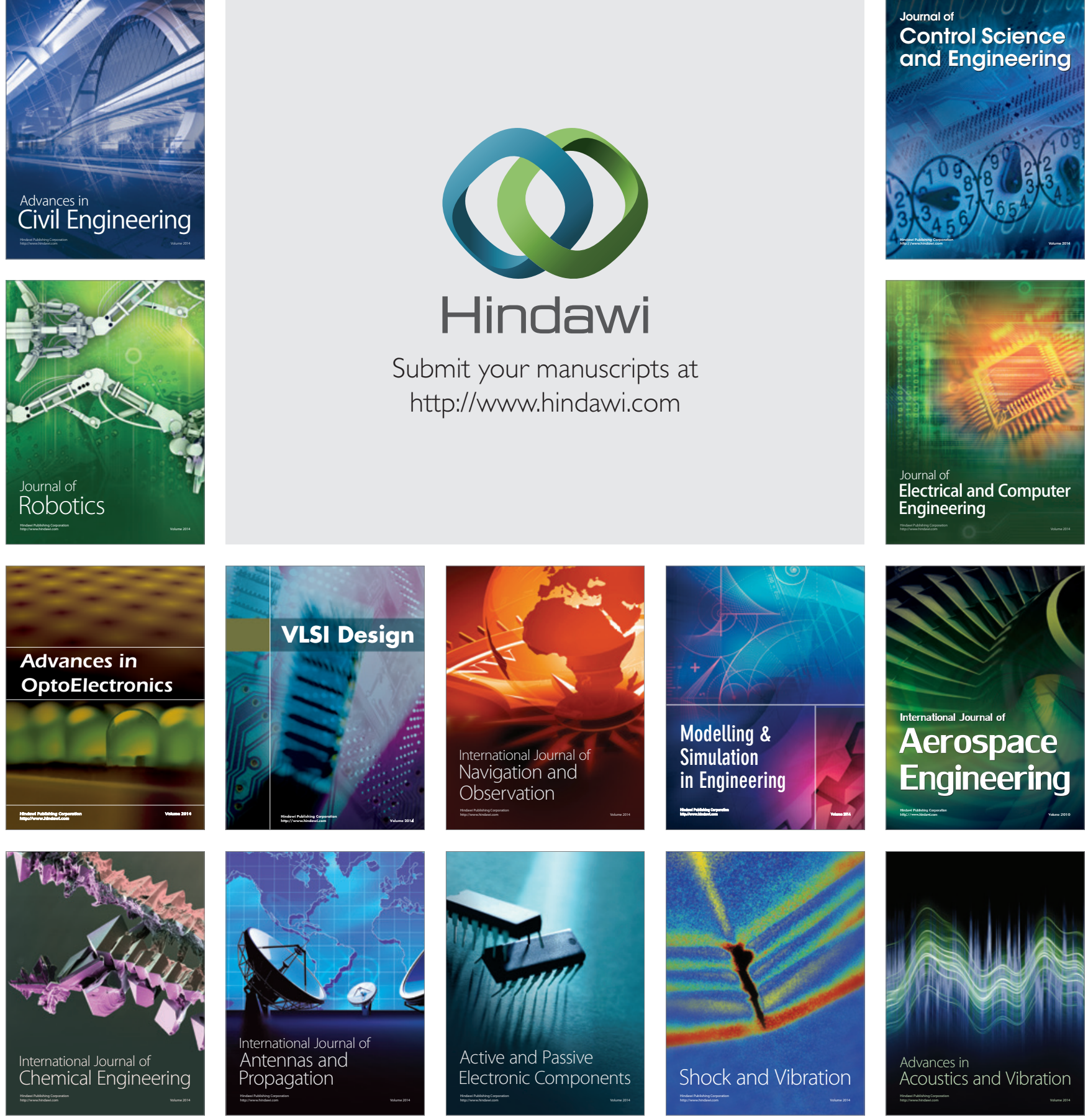